\title{
An unusual origin of Ewing sarcoma
}

\section{Juvva Kishan Srikanth', Rajendra Kumar', Nitesh Gupta', Pranav Ish', Rohit Kumar', Neeraj Kumar Gupta ${ }^{1}$}

'Vardhman Mahavir Medical College \& Safdarjung Hospital, New Delhi, India

${ }^{2}$ Rangaraya Medical College, Kakinada, Andhra Pradesh, India

An 18-year-old boy presented with right-sided chest tightness for 2 months. There was no fever, cough or wheeze. There was loss of weight and appetite for 1 month. There was no relevant medical or surgical history in the past. On examination, there were decreased movement, dull percussion note and decreased breath sounds in mammary, infraaxillary and infrascapular areas of the right side.

The chest roentgenogram showed a homogeneous opacity in right mid and lower zones silhouetting the right heart border, cardiophrenic angle and diaphragm. A bedside ultrasonography revealed a complex lesion with thick septations and few solid areas. The differentials included sarcomas of the chest wall, large solitary fibrous tumour and metastases. A subsequent contrast-enhanced computed tomography of the chest (CECT) (Figure 1) documented the lesion to be located in the paravertebral region, with heterogeneous densities inside, extending from the level of the $5^{\text {th }}-12^{\text {th }}$ thoracic vertebra indenting the posterio-superior surface of the right lobe of the liver with no underlying bone changes. A CT-guided biopsy revealed small blue round cells and trabeculae with areas of necrosis and haemorrhage which were CD-99 positive, establishing diagnosis of extraskeletal Ewing sarcoma (EES). On the multidisciplinary tumour board, thoracotomy was planned followed

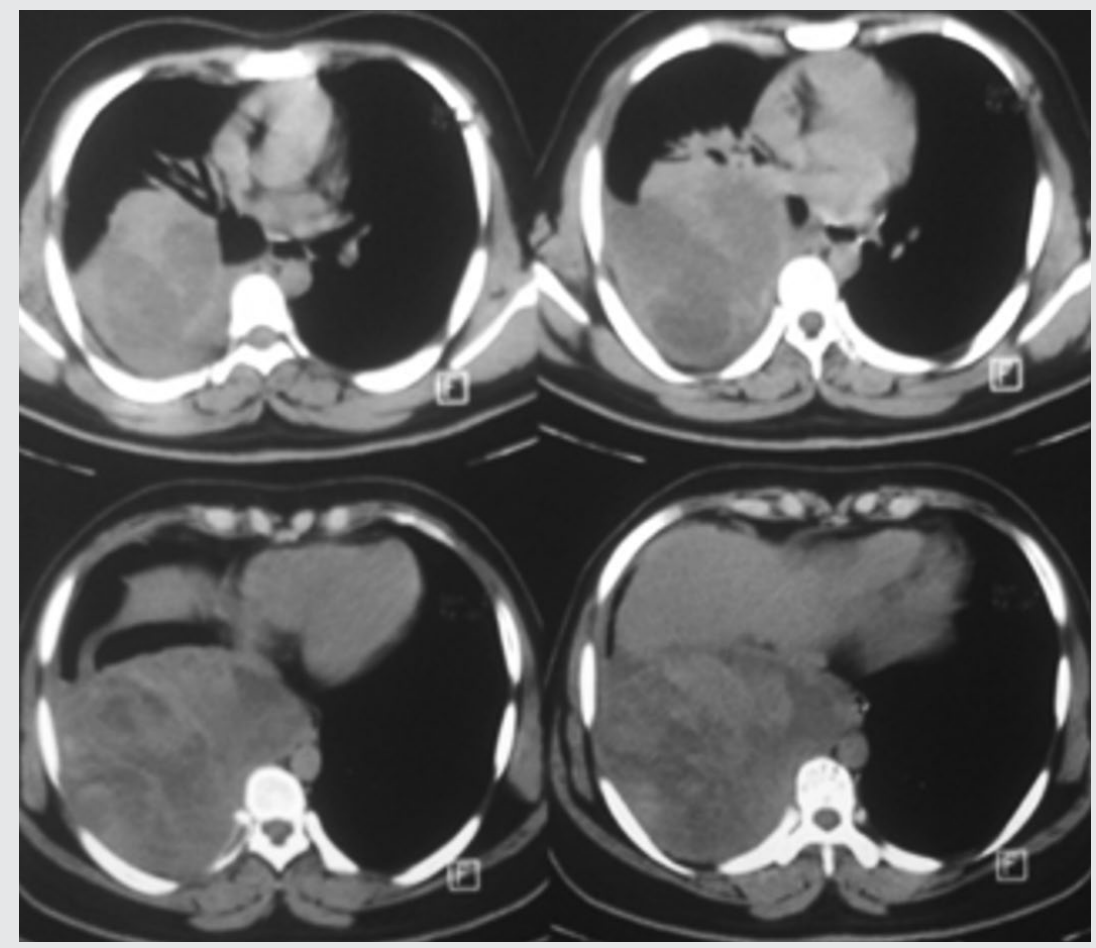

Figure 1. CT thorax showing a large heterogeneous lesion occupying the right hemithorax inferiorly having absent fat planes with the T5 to T12 vertebrae, overlying ribs and right hemidiaphragm. The right dome of liver is indented and pushed inferiorly. Internal areas of cystic attenuation are noted indicating necrosis

Address for correspondence: Pranav Ish, Vardhman Mahavir Medical College \& Safdarjung Hospital, New Delhi, India; e-mail: pranavish2512@gmail.com Conflict of interest: None declared

DOI: 10.5603/ARM.a2021.0044 | Received: 20.01.2020 | Copyright C 2021 PTChP | ISSN 2451-4934 | e-ISSN 2543-6031

This article is available in open access under Creative Common Attribution-Non-Commercial-No Derivatives 4.0 International (CC BY-NC-ND 4.0) license, allowing to download articles and share them with others as long as they credit the authors and the publisher, but without permission to change them in any way or use them commercially. 
by adjuvant chemotherapy (vincristine, doxorubicin, and cyclophosphamide, alternating with ifosfamide and etoposide).

The Ewing sarcoma family of tumours (EFT) consists of classic Ewing sarcoma of the bone, extraskeletal Ewing sarcoma (EES), malignant small-cell tumour of the thoracopulmonary region (Askin's tumour) [1] and primitive neuroectodermal tumours of the bone or soft tissues. EES has an uncommon incidence of around $1.1 \%$ of all malignant soft tissue tumours, predominantly in adolescents and young adults (10-30 years) [2]. EES commonly affects the extremities, soft tissues of the trunk (intercostal regions), head and neck, pelvis, and peritoneum. The tumour tends to spread locally, invading muscles or skeletal structures [3].

In the current case, however, the tumour was located in the paravertebral region and did not invade the adjacent soft tissue or bony structures. The surgery was uneventful, following which the patient was initiated on adjuvant chemotherapy and has no evidence of recurrence yet. EES has a favourable five-year survival $(61 \%)$ in comparison to skeletal Ewing's Sarcoma (10\%) depending on age, size and location of tumour along with response to therapy.

To conclude, EES should be considered as a differential for heterogeneous lesions of the chest wall on radiology.

\section{References:}

1. Kuni SP, Gupta N, Cherath SK, et al. A 22-year-old man with back pain, dilated veins over chest, and mass in right atrium. Chest. 2020; 158(6): e335-e341, doi: 10.1016/j.chest.2020.07.055, indexed in Pubmed: 33280779.

2. Khatib WM, Jagtap SV, Kaleet P. et. al. Primary extra skeletal ewing sarcoma presenting as soft tissue mass diagnosed on fine needle aspiration cytology. Int J Health Sci Res. 2015; 5(10): 377-380.

3. Isefuku S, Seki M, Tajino T, et al. Ewing's sarcoma in the spinal nerve root: a case report and review of the literature. Tohoku J Exp Med. 2006; 209(4): 369-377, doi: 10.1620/tjem.209.369, indexed in Pubmed: 16864960.

4. Ahmad R, Mayol B, Davis M, et al. Extraskeletal Ewing's sarcoma. Cancer. 1999; 85(3): 725-731, doi: 10.1002/(sici)1097-0142(199 90201)85:3<725::aid-cncr23>3.0.co;2-2. 